\title{
PAPERS
}

\section{The need for prophylactic treatment to the central nervous system in patients with aggressive non-Hodgkin's lymphoma}

\author{
C. J. HAWKEY \\ B.A., B.M., M.R.C.P. \\ P. J. TOGHILL \\ M.D., F.R.C.P. \\ University Hospital, Queen's Medical Centre, Nottingham NG7 2UH
}

\begin{abstract}
Summary
During 2 years, 6 out of 34 patients presenting with newly diagnosed non-Hodgkin's lymphoma developed central nervous system (CNS) complications. All were male and had diffuse, undifferentiated lymphomas. In all 6 patients, CNS disease developed during, or shortly after, treatment. We suggest that a group at high risk from these complications can be identified and should be considered for a trial of prophylaxis.
\end{abstract}

KEY WORDS: lymphoma, central nervous system, treatment.

\section{Introduction}

Involvement of the central nervous system (CNS) in non-Hodgkin's lymphoma (NHL) is now more frequently recognized. In the majority of patients, it is diagnosed when there is advanced disease elsewhere (Young et al., 1979), but in some it may be the first manifestation of the lymphoma (Littman and Wang, 1975; Venables et al., 1980). In some patients, CNS disease may develop during or after treatment. Under these circumstances, the CNS acts as a sanctuary site inaccessible to most conventional chemotherapeutic agents.

In 34 consecutive newly diagnosed patients with non-Hodgkin's lymphoma in Nottingham, 6 developed CNS disease. All 6 were male and had diffuse undifferentiated lymphomas. All developed CNS disease during, or shortly after, concluding treatment with a modification of the CHOP regimen described originally by McKelvey et al. (1976) and used by the British National Lymphoma Investigation (BNLI) for the treatment of advanced high grade NHL. None of the cytotoxic drugs employed in this regimen crosses the blood-brain barrier and our experience of CNS relapse in the face of recent or continuing chemotherapy suggests there is a need for a controlled trial of additional treatment as prophylaxis against CNS disease in such high risk patients.

\section{Patients}

The patients described were seen at University Hospital, Nottingham during 1980 and 1981. The clinical details are summarized in Tables 1 and 2 . In 5 of the 6 patients, the diagnosis was established on lymph node biopsy, but in Case 5 , it was made by histological examination of the testis after orchidectomy for painless swelling. Pathological material in 5 of the patients was examined additionally by the Pathology Panel of the British National Lymphoma Investigation (BNLI) and was classified accordingly (Jelliffe and Vaughan-Hudson, 1981).

All patients were staged according to the recommendations of the BNLI. Five patients had widespread disease with marrow involvement (Stage IV) on presentation. Case 3 was initially regarded as having limited mediastinal disease (Stage IIA) on the basis of a staging laparotomy. However, whilst undergoing radiotherapy, it became clear that the disease had rapidly disseminated with bone and marrow involvement. The cerebrospinal fluid (CSF) was examined routinely by cytocentrifugation on diagnosis in all patients, except Case 6, and was, at that time, within normal limits.

Chemotherapy with the modified CHOP regimen consisted of pulsed intravenous injections of cyclophosphamide $750 \mathrm{mg} / \mathrm{m}^{2}$, adriamycin $25 \mathrm{mg} / \mathrm{m}^{2}$ and vincristine $1.4 \mathrm{mg} / \mathrm{m}^{2}$ given on days 1 and 8 with prednisone orally $40 \mathrm{mg} / \mathrm{m}^{2}$ from day 1 to day 8 inclusive. (McKelvey et al., 1976). Courses were given every 4 to 6 weeks depending on the peripheral blood counts to a minimum of 6 courses and at least 3 courses after complete remission.

In patients 1 and 3, CNS involvement appeared during treatment with CHOP at a time when there appeared to be remission of the disease elsewhere. In patients 2 and 5, CNS disease appeared shortly after the patients completed therapy with CHOP and had achieved clinical remission. In 2 patients (Cases 4 
TABLE 1. Clinical details of 6 patients with non-Hodgkin's lymphoma and CNS involvement (see also Table 2)

\begin{tabular}{|c|c|c|c|c|c|c|}
\hline Case & $\begin{array}{c}\text { Age at } \\
\text { diagnosis }\end{array}$ & Sex & $\begin{array}{l}\text { Clinical presentation } \\
\text { and staging after } \\
\text { initial investigation }\end{array}$ & $\begin{array}{l}\text { Histological } \\
\text { diagnosis }\end{array}$ & Treatment & $\begin{array}{c}\text { Duration from } \\
\text { diagnosis to } \\
\text { onset of } \\
\text { neurological disease }\end{array}$ \\
\hline 1 & 59 & $\mathbf{M}$ & $\begin{array}{l}\text { Fever, } \\
\text { abdominal mass and } \\
\text { inguinal nodes } \\
\text { Stage* IV B }\end{array}$ & $\begin{array}{l}\text { Unclassified } \\
\text { (BNLI)* }\end{array}$ & $\mathrm{CHOP}^{*} \times 3$ & 3 months \\
\hline 2 & 64 & $\mathbf{M}$ & $\begin{array}{l}\text { Glands in neck } \\
\text { Stage IV A }\end{array}$ & $\begin{array}{l}\text { Undifferentiated } \\
\text { large cell (lymphoid) } \\
\text { (BNLI) }\end{array}$ & $\mathrm{CHOP} \times 6$ & 8 months \\
\hline 3 & 29 & $\mathbf{M}$ & $\begin{array}{l}\text { Glands in neck } \\
\text { and mediastinum } \\
\text { Stage II A } \\
(\rightarrow \text { Stage IV A } \\
\text { during treatment })\end{array}$ & $\begin{array}{l}\text { Undifferentiated } \\
\text { large cell (lymphoid) } \\
\text { (BNLI) }\end{array}$ & $\begin{array}{l}\text { DXR to } \\
\text { mediastinum. } \\
\text { CHOP } \times 6\end{array}$ & 6 months \\
\hline 4 & 47 & $\mathbf{M}$ & $\begin{array}{l}\text { Glands in neck, } \\
\text { fever } \\
\text { Stage IV B }\end{array}$ & $\begin{array}{l}\text { Unclassified } \\
\text { (BNLI) }\end{array}$ & $\mathrm{CHOP} \times 2$ & 3 months \\
\hline 5 & 53 & $\mathbf{M}$ & $\begin{array}{l}\text { Testicular swelling, } \\
\text { lung infiltration } \\
\text { Stage IV A }\end{array}$ & $\begin{array}{l}\text { Undifferentiated } \\
\text { large cell (lymphoid) } \\
\text { (BNLI) }\end{array}$ & $\mathrm{CHOP} \times 6$ & 8 months \\
\hline 6 & 66 & $\mathbf{M}$ & $\begin{array}{l}\text { Weakness, } \\
\text { lymphadenopathy } \\
\text { Stage IV B }\end{array}$ & $\begin{array}{l}\text { Diffuse lymphocytic } \\
\text { lymphoma }\end{array}$ & $\mathrm{CHOP} \times 3$ & 3 months \\
\hline
\end{tabular}

*See text for details.

and 6), CNS disease developed during early CHOP therapy.

No consistent regime of CNS therapy was given as patients had received variable amounts of chemotherapy at the stage of CNS involvement. Case 2 required urgent neurosurgery with ventricular shunting for his communicating hydrocephalus and was later treated with cranial irradiation and intra-thecal methotrexate. All other patients received intra-thecal methotrexate in dosages of 10-15 mg weekly up to 6 weeks. Additionally, Cases 3 and 5 received cranial irradiation (Table 2). Post-mortem examination in cases 1 and 5 revealed generalized relapse of the nonHodgkin's lymphoma as well as extensive CNS disease.

\section{Discussion}

Our own experience in this 2-year period confirms recent suggestions that CNS involvement, particularly lymphomatous leptomeningitis in diffuse nonHodgkin's lymphoma is becoming more common (Littman and Wang, 1975; Young et al., 1979; Bunn et al., 1976; Levitt et al., 1980). Whilst part of this increase may be attributable to improvements in diagnosis, such as identification of malignant cells in the CSF after centrifugation and isotope and computer assisted tomographic (CAT) scanning, these are unlikely to be the sole determinant factors. Much of the increase is likely to be due to the emergence of new disease syndromes arising from intensive che- motherapeutic regimes in patients with diffuse age̊ gressive non-Hodgkin's lymphoma. Improved survi val using combination chemotherapy, as typified be the CHOP regimen, has presumably extended survi val only to allow the extension of disease to sanctuary sites such as the central nervous system.

Differences in histological nomenclature render direct comparisons with other studies difficult, but all reports confirm a much greater risk of CNS complications with diffuse histiocytic and diffuse undifferentiated lymphoma using the Rappoport classification. Using the BNLI nomenclature, 3 of our own patients have had undifferentiated large cell (lymphoid) disease and 2 others have had highly malignant diffuse lymphoid tumours which defied accurate classification. CNS disease is usually associated with bone marrow involvement though in a third of cases this may only be detected at postmortem examination (Young et al., 1979). In 5 of our own cases, lymphomatous infiltration of the bone marrow was seen at presentation. Law et al. (1975) have suggested that lymphoma with retroperitoneal involvement might have predilection for CNS relapse, as was the situation with Case 1. One of our patients (Case 5), had testicular swelling as an initial symptom and Wolley et al. (1976) proposed that that type of clinical presentation might predispose to CNS disease later.

The analogy between CNS involvement in diffuse non-Hodgkin's lymphoma and acute lymphoblastic leukaemia cannot be avoided and prompts the 


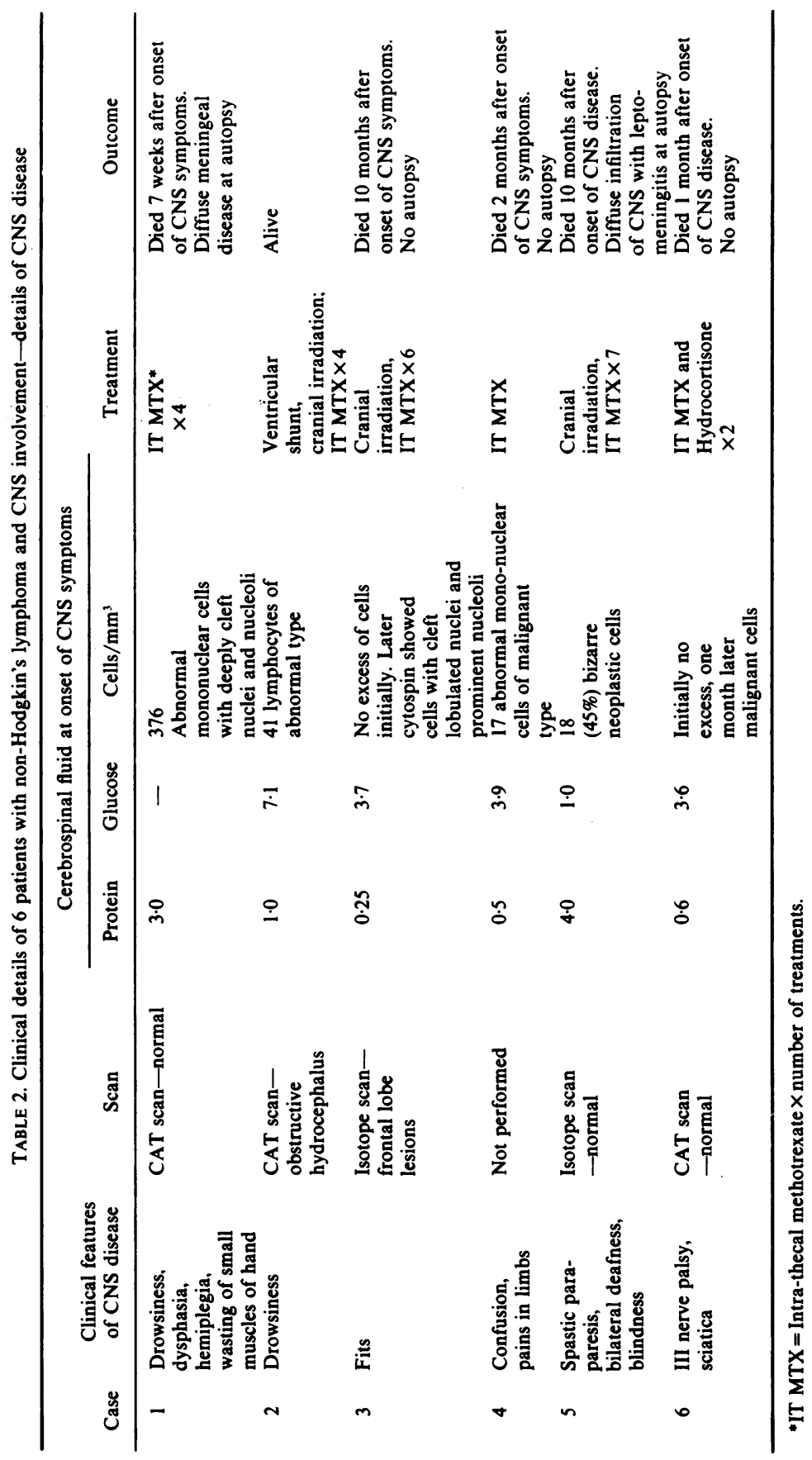


suggestion that this is 'leukaemia revisited' (Bunn et al., 1976). Certainly, in the absence of specific CNS prophylaxis in acute lymphoblastic leukaemia, a high proportion of patients develop infiltration of the meninges within 2 years. CNS prophylaxis with cranial irradiation and intra-thecal methotrexate has been clearly shown to improve the prognosis of acute lymphoblastic leukaemia in children (Working Party on Leukaemia in Childhood, 1973; Dritschilo et al., 1976) and in adults (Lister et al., 1978b).

A number of studies have suggested that a related approach ought to be of value in adult NHL. High doses of both methotrexate and cytosine arabinoside given by continuous intravenous infusion can achieve cytotoxic concentrations in the CSF (Tattersall et al., 1975; Weinstein et al., 1978). In the case of methotrexate, intravenous infusion has been shown to give a more uniform distribution in the CNS than intra-thecal administration (Shapiro, Young and Mehta, 1975). High dose methotrexate administered to patients with unfavourable NHL in relapse with CNS disease has produced appreciable improvement (Skarin et al., 1977), but at present it is most unlikely that complete erradication can be achieved once overt CNS disease has developed (Schein et al., 1976; Young et al., 1979; Lister et al., 1978a).

The addition of methotrexate to regimes such as BACOP/D (bleomycin, adriamycin, cyclophosphamide, vinicristine and prednisone or dexamethasone) in the initial treatment of patients with diffuse histiocytic or undifferentiated lymphomas has produced encouraging results with only one patient with CNS relapse in a series of 30 patients treated by Canellos, Lister and Skarin (1978). Also, the use of methotrexate and cytoxine arabinoside may account for the lack of CNS relapses seen with the COMLA (cyclophosphamide, vinicristine, methotrexate with leukovorin rescue and cytarabine) regimen (Sweet $\boldsymbol{e t}$ al., 1980). Combined cranial irradiation and intrathecal methotrexate has been used after induction of systemic remission in aggressive NHL in adults (Lister et al., 1978a) and has proved effective in children (Murphy and Hustu, 1980).

All the patients treated by these regimens had diffuse histiocytic or undifferentiated lymphomas and CNS disease in nodular lymphoma is rare. Our results support the suggestion of Young and his colleagues (1979) that CNS prophylaxis is only warranted in patients with advanced diffuse histiocytic or undifferentiated lymphomas. Results with the M-BACOP/D and COMLA regimes have highlighted the benefits that might accrue from the addition of methotrexate or cytosine arabinoside, but concurrent control groups have not been used for comparison.

Apart from its inadequacy with respect to CNS relapse, CHOP is an effective regime (McKelvey et al., 1976; Armitage et al., 1980) and is widely used for the treatment of advanced NHL. We suggest that a controlled trial to evaluate the efficacy of additional 2 CNS prophylaxis with methotrexate and craniospinal irradiation would be ethical and timely.

\section{References}

Armitage, J.O., Corder, M.P., Leimert, J.T., DiCK, F.R. \& $\overparen{D}$ EllioTT, T.E. (1980) Advanced diffuse histiocytic lymphoma treated with cyclophosphamide, doxorubicin, vincristine and $\omega$ prednisone. Cancer Treatment Reports, 64, 649.

BunN, P.A., Schein, P.S., BANKS, P.M. \& DE VITA, V.T. (1976) Central nervous complications in patients with diffuse histiocytic $\vec{A}$ and undifferentiated lymphoma. Leukaemia revisited. Blood, 47, $\vec{\omega}$ 3.

Canellos, G.P., Lister, T.A. \& Skarin, A.T. (1978) Chemo- Øृ therapy of the non-Hodgkin's lymphomas. Cancer, 42, 932.

Dritschilo, A., Cassady, J.R., Camitta, B., JaFFe, N., FuRman, iv L. \& TRAGGIS, D. (1976) The role of irradiation in central nervous 6 system treatment and prophylaxis for acute lymphoblastic leukaemia. Cancer, 37, 2729.

Jellife, A.M. \& VAUghan-Hudson, G. (1981) The evolution of the British National Lymphoma Investigation. (Report No. 5). Clinical Radiology, 32, 483.

LAW, I.P., DICK, F.R., BLOM, J. \& BERGEVIN, P.R. (1975) Involve- 음 ment of the CNS in non-Hodgkin's lymphoma. Cancer, 36, 225. -

LEviTT, L.J., DAwSON, D.M., Rosenthal, D.S. \& MoloneY, W.C. $\backslash$ (1980) CNS involvement in the non-Hodgkin's lymphoma. Cancer, 45, 545.

Lister, T.A., Cullen, M.H., Brearley, R.B., Beard, M.E.凡 Stansfield, A.G., Whitehouse, J.M.A., Wrigley, P.F.M FORD, J.M., MALPAS, J.S. \& CROWTHER, D. (1978a) Combinatiơ chemotherapy for advanced non-Hodgkin's lymphoma of un vourable histology. Cancer Chemotherapy and Pharmacology, 107.

LISTER, T.A., Whitehouse, J.M.A., BEARD, M.E.J., BREARLEY, R.L., Wrigley, P.F.M., Oliver, R.T.D., FreEMAN, J.E., WOO- 으 DRUFF, R.K., MALPAS, J.S., PAXTON, A.M. \& CROWTHER, D. Q (1978b). Combination chemotherapy for acute lymphoblastic $\overrightarrow{\vec{T}}$ leukaemia in adults. British Medical Journal, 1, 199.

LITTMAN, P. \& WANG, C.C. (1975) Reticular cell sarcoma of the brain. Cancer, 35, 1412.

MCKelvey, E.M., Gottlieb, J.A., Wilson, H.E., Haut, A., TalLEY, R.W., Staphens, R., LANE, M., Gamble, J.F., Jones, S.E., Grozea, P.N., Gutterman, J., Coltman, C. \& Moon, T.D. (1976) Hydroxylduanomycin (adriamycin) combination chemotherapy in malignant lymphoma. Cancer, 38, 1484.

MURPHY, S.B. \& HUSTU, H.O. (1980) A randomized trial of combined modality therapy of childhood non-Hodgkin's lym- o phoma. Cancer, 45, 630.

Schein, P.S., De Vita, V.T., Hubbard, S., Chabner, B.A., CanelLOS, G.C., BERARD, C. \& YouNG, R.C. (1976) Bleomycin, adriamycin, cyclophosphamide, vincristine and prednisone (BA- I COP) combination chemotherapy in the treatment of advanced 음 diffuse histocytic lymphoma. Annals of Internal Medicine, 85, 417.

SHAPIRO, W.R., YOUNG, D.F. \& MEHTA, B.M. (1975) Methotrexate: N Distribution in cerebro-spinal fluid after intravenous, ventricular and lumbar injections. New England Journal of Medicine, 293, 161. N

Skarin, A.T., Zuckermann, K.S., Pitman, S.W., Moloney, W., N Frei, F. \& Canellos, G.P. (1977) High dose methotrexate with folinic acid in the treatment of advanced non-Hodgkin's lymphoma including CNS involvement. Blood, 50, 1039.

Sweet, D.L., Golomb, H.M., UltmanN, J.E., Miller, J.B., Stein, R.S., Lester, E.P., MinTz, U., Bitran, J.D., STrelli, R.A., \& DAILY, K. \& ROTH, N.O. (1980) Cyclophosphamide, vincristine, methotrexate with leukovorin rescue and cytarabine (COMLA) combination segmental chemotherapy for advanced diffuse histocytic lymphoma. Annals of Internal Medicine, 92, 785. 
Tattersall, M.H.N., Parker, L.M., Pitman, S.W. \& Frei, E. (1975) Clinical pharmacology of high-dose methotrexate (NCS740). Cancer and Chemotherapy Reports, 6, 25.

Venables, G.S., Proctor, S.J., Bates, D., Cartlidge, N.E.F. \& SHAW, D.A. (1980) Intra-cranial disease in non-Hodgkin's lymphoma. Quarterly Journal of Medicine, 49, 111.

Weinstein, H., Griffin, T., Cohen, H., Propper, R. \& Sallan, S. (1978) Pharmacology of cytosine arabinoside. Proceedings of the American Association of Cancer Research, 19, 157.

WOLLEY, P.V., OSBORNE, C.K., LEVI, J.A., WIERNIK, P.H. \& CANEL-
Los, G.A. (1976) Extra-nodal presentation of non-Hodgkin's lymphomas in the testis. Cancer, 38, 1026.

WORKINg ParTY ON LeUKAEMIA IN ChILDHOOd (1973) Treatment of acute lymphoblastic leukaemia. Effect of prophylactic therapy against central nervous system leukaemia. British Medical Journal, ii, 381 .

Young, R.C., Howser, D.M., ANDERSON, T., Fisher, R.I., JAFFE, E. \& DE VITA, V.T. (1979) Central nervous system complications of non-Hodgkin's lymphoma. American Journal of Medicine, 6, 435.

(Accepted 25 November 1982) 